\title{
Health and Society: reflections on policy
}

\author{
Alastair McI. Gray
}

\section{'Their' Problems and 'Our' Problems}

In an earlier issue of this Bulletin, a plea was entered that the traditional focus of development studies on the developing countries should be recognised as unviable and harmful: "the assumption that "their" problems are intrinsically different from "ours" is not merely patronising; it has become a hindrance to the transfer of experience' [Seers 1977]. But in the context of health and health policy, the differences are in some senses so glaring that such a view is difficult to sustain. 'Our' problems seem increasingly to focus on the need to find ways of containing health care costs, which now account for between 5 and 10 per cent of GNP in industrial countries; 'their' problems include the fact that whatever is done must be done with per capita health care expenditures in some cases a hundred times smaller than those in Europe or North America. 'Our' problems are related to an increasing elderly dependent population associated with an average expectation of life at birth in the mid-70s and birth rates at or below replacement level; 'their' problems are an expectation of life barely two-thirds of ours, and an infant mortality rate 10 to 20 times higher. ' $W$ ' concern ourselves with the ethics of artificial life support and infertility technology, while 'they' have just cause to wonder at the ethics of a world political order in which the two superpowers alone devote to military expenditure each week more than twice the resources required in a year to mount an effective global campaign of malaria eradication.

In short, certain intrinsic differences in health experience undoubtedly do exist between 'us' and 'them', and moreover show no obvious signs of markedly diminishing. However, recent developments in health policy in the industrial countries, coupled with the continuing debate over the historical processes which accompanied the improvement in health status among their populations, suggest that there may indeed be some scope for the 'transfer of experience'. In particular, by reviewing the role of health care - and health care policy - in altering health experience in countries such as Britain, some small but significant lessons may be learnt.

\section{Health and Health Care: a retrospective view}

The historical debate over the contribution of health care to health has become closely associated with the work of Cochrane and McKeown [Cochrane 1971, 1978; McKeown 1965, 1974, 1976, 1979], although it has become entangled with a wider critique of modern medicine [eg Illich 1975]. The epidemiological foundations and empirical substance of the hypotheses of Cochrane and McKeown contrast so strongly with the sweeping ideological assault by Illich that much is to be gained by considering them separately.

The essence of McKeown's argument is that the rapid rate of increase in the population of Britain from the 18 th century onwards was largely due to a decline in the death rate, and that this decline had much more to do with improvements in nutrition, housing, hygiene, sanit ation and the general standard of living than with advances in medical knowledge and practice in the sense of 'specific preventive and therapeutic measures applied to the individual' [McKeown 1976:3]. For the present purposes we are concerned with the link between the death rate and medical practice rather than the link between the death rate and population change; it is worth noting, however, that McKeown's position on the latter relationship has turned out to be rather extreme. Wrigley and Schofield [1981] have shown conclusively the relatively much greater significance of increasing fertility than falling mortality, at least during the 18 th century.

It is also important to note that McKeown acknowledges a number of genuine developments in medicine from the 18 th century onwards, including a growth in hospital midwifery. A key part of his argument, however, is that important scientific or technical advances may be of little practical significance to people until considerable time has passed, so that medical discovery must be distinguished from the process and impact of medical practice. This point is frequently overlooked.

The progressive decline in respiratory tuberculosis as a cause of death in England and Wales from the mid- 
19 th century onwards clearly illustrates these points. of all the major infectious diseases, respiratory tuberculosis was by far the most widespread, and during the 19th century was in fact the largest single cause of death. In 1838 the death rate was approximately 4,000 per million; by 1882 , the year the tubercle bacillus was identified, the death rate had fallen below 2,000 per million; and by the late 1940 s/early 1950s, when chemotherapy and immunisation became available, the death rate was under 500 per million and still falling. Similar patterns are to be observed for pneumonia, whooping cough and measles. Mortality from water- and food-borne infections (such as the diarrhoeal diseases and typhoid) decreased rapidly after the sanitary reforms of the late 19th century before there were effective therapeutic measures. These patterns led McKeown to conclude that immunisation and treatment contributed little to the reduction of deaths from infectious diseases before 1935, and over the whole period since cause of death was first registered (in 1838) they were much less important than other influences' [McKeown 1976: 108]

These 'other influences' took two principal forms: a reduction in exposure to infection, and an increase in resistance to infection as a result of improvement in nutritional status. The reduction in exposure was in fact quite uneven. Over the century up to 1935 , improved water supply and sewage disposal reduced the degree of exposure to water- and food-borne infections, but exposure to air-borne infections if anything increased with the acceleration of industrialisation, urbanisation and overcrowding, and the declining mortality probably resulted from improving levels of nutrition. Of the many implications which flow from this analysis, two in particular may be identified. First, in relation to water- and food-borne infectious disease, significant improvement awaited the implementation of major public health measures: 'it is the condition of the water and food which determines the risks of infection, rather than the cleanliness of the hands or utensils on which they are brought to the mouth' [McKeown 1976:124]. Second, the connection between nutritional status and the outcome of infection is very strong, so that where malnutrition is widespread its health impact is correspondingly pervasive.

Within the framework offered by McKeown there is no necessary contradiction between the potential effectiveness of medical practice and its small historical contribution to the improvements in health in industrial countries over the last 200 years. Cochrane, while attaching the same general importance as McKeown to improvements in standards of living and public health measures, has also developed a more detailed critique of medical practice itself, and in particular of the widespread use of therapies, procedures, technologies and techniques, the effectiveness of which has never been investigated systematically. Numerous examples could be cited of the introduction and diffusion of medical practices which turned out to be ineffective, and as Abel-Smith has noted, 'it is estimated that only 10 to 20 per cent of treatments have ever been validated by the stern test of controlled trials' [Abel-Smith 1981:218]. Only in a limited sense, however, is Cochrane arguing that the effectiveness of medical practice as a whole is limited. Rather, the central thrust of his criticism continues to be the lack of control mechanisms surrounding the use and innovation of specific treatments, which may or may not have a positive effect on health, and may or may not be an improvement on existing or alternative treatments.

In this Cochrane has little common ground with Illich, whose critique is based on the premise that modern medicine not only has contributed little or nothing to the improvement in health, but has in fact come to exert a deleterious influence on morbidity and mortality, and can itself be likened to an epidemic. Illich is not to be categorised easily or tackled at a single point. In the present context the most significant point to note is the almost complete exclusion from consideration in his analysis of any possibly positive contributions by modern medicine, and his emphasis on curative measures when making this assessment, with the consequent neglect of the role of medical care in reducing disability and discomfort [Navarro 1975].

The critiques of contemporary medicine by Cochrane and McKeown, although widely influential, are not without critics. Perhaps the most penetrating remarks have come from Tudor Hart [1981], who has focused on the interpretation of the evidence cited rather than challenging the evidence itself. He notes the connection between the substance of the critique and the 'limits of professionalism' - that is, the present passivity in the social role of doctors, as they respond to individual complaints of disease rather than promoting the collective conservation and promotion of health. The consequence of these limits to professionalism is a failure to make full use of existing effective medical knowledge. This is illustrated by a re-examination of the evidence cited by McKeown in relation to diphtheria, the infectious disease "in which it is most difficult to assess precisely the time and influence of therapeutic measures' [McKeown 1976:98]. Tudor Hart directs attention to the long period which elapsed between the discovery of effective immunisation in 1913 and the first national immunisation campaign in 1942, a delay which occurred despite repeated advocacy of mass immunisation. The medical profession, having defined immunisation as a medical concern, then neglected it in favour of 'heroic 
cures', and the study of individual symptoms and early diagnosis, while each year diphtheria continued to claim the lives of around 3,000 children. 'Not for the last time', writes Tudor Hart, 'we claimed as our own, territory we were unable or unwilling to occupy' [Tudor Hart 1981:872]. Thus, whereas McKeown seems content to demonstrate that medical intervention was either too late or too ineffective to influence the decline in certain diseases, Tudor Hart has consistently argued that intervention could have been much more influential had the legitimate parameters of the medical profession's sphere of activity been less restrictive. Insofar as Tudor Hart maintains that this is still the case, he is clearly claiming a much more important potential role for medicine than would McKeown.

The lines of this debate should now be emerging sufficiently strongly to direct us towards some policy implications. To recapitulate, there is little evidence that medical practice has made major historical contributions to decreased mortality rates in Western industrialised countries. The medical profession itself has suffered from a combination of self-imposed limits, which largely restrict the 'medical' to responding to sick individuals, may prevent or delay the extension of effective knowledge and treatment to the sick population, and often obstruct a clear view of the wider influences on health and ill-health. A confluence of circumstances, in particular the soaring cost of health care in virtually all industrialised countries, and the increasing accuracy with which modern epidemiology can assess the effectiveness of therapies, has combined to place a larger questionmark against the adequacy of existing health care policy today than for a very long time, and has injected a substantial contemporary relevance into this historical debate.

\section{Health Policy Proposals in Britain: the 'Black Report'}

The original objectives of the national health service in Britain were: an equal opportunity for all to benefit from the best available; comprehensive health care; and the promotion of good health as well as the treatment of disease. It has long been evident that these goals have been only partially achieved, although the great improvements over the 'deplorable state of the old medical system' [Eckstein 1958:44] have been no small achievement. In particular, it has become clear that the geographical distribution of resources has remained very uneven, and that social class differences in death rates and life expectancy continue to show significant inequalities [Cooper and Culyer 1971, Morris 1959, 1979, Townsend 1974]. What is less clear is the set of factors that influence these inequalities. In some instances, such as the geographical distribution of resources, it has been possible to devise policies which could be implemented from within the health service without serious obstacle. In other instances policies similarly devised to be pursued primarily by the health service have met internal impediments. The proposals to alter priorities - for instance by gradually increasing the relative volume of resources devoted to specified patientgroups - show no real sign of biting into the present pattern of health service provision. This appears to be in part because the policies go no further than the exhortation of those involved, and in part because the policy-defined areas of low priority for additional resources (acute medicine and surgery) and the highpriority areas (geriatrics, mental handicap and deficiency) are ranked in almost exactly inverse order to the rankings of status, reward, and professional interest fostered within medicine [Gray and Hunter 1983].

Difficult as these obstacles are, they could be overcome given sufficient will and determination. Much more daunting has been the increasingly widespread rediscovery that the origins of much illhealth, and hence the real solutions, still largely lie among the material circumstances of people's lives: among the levels of nutrition, housing conditions, employment and working environment, which the health service is naturally incapable of seriously altering. It seems strange how comprehensively this lesson has been neglected, and how slowly the contours of the 'new/old' critique are being recognised. For instance, it remains the case that measurement of expenditure on disease prevention invariably focuses on a few advertising campaigns, and excludes the water and sewage industry, as if this were something else altogether. The most elaborate British restatement of this analysis, and the most massively supported statistically, is the report of the DHSS-sponsored working group on inequalities in health - the 'Black Report' - published in 1980.

The Black Report drew its conclusions from a large volume of pre-existing empirical material, and indeed its account of trends and present patterns of health inequalities offered nothing essentially new or unknown. It stated that despite the existence for more than three decades of a national health service with some form of equality as one of its objectives, it seemed that at all stages of life, morbidity and mortality were significantly greater in the lower occupational groups. Thus the perinatal death rate was shown to be twice as high in occupational class $\mathrm{V}$ (unskilled workers) as in occupational class I (professionals, executives), and the post-neonatal death rate (that is, deaths between one month and one year after birth) was five times higher. For those aged 15-64, the risk of death before reaching retirement was 
seen to be around twice as high in class $\mathrm{V}$ as class I, and these patterns were found to be repeated for most of the main causes of death and available measures of morbidity. Even more disquieting was the suggestion by the report that these inequalities had not only continued to exist, but they did not seem to be improving and were in some respects deteriorating. For instance, the difference in mortality rates of men and women was shown to have widened over time; the occupational class gradient of mortality was steeper for economically active men in the 1970s than it had been 20 years previously; and the relative mortality rates of married and single women of all ages in occupational class IV (semi-skilled workers) has been deteriorating steadily.

Where the Black Report signalled a more obvious innovation as compared with previous investigations was in the proposals and recommendations put forward to redress these inequalities. It assumed that just as the main influences on health inequalities lay well outside the reach of the health service - in the working and living conditions, and the overall material and social circumstances of people's lives so conventional health care policy could play but a relatively small role in a wide-reaching strategy for health which would encompass these material and social circumstances. Therefore recommendations such as improved antenatal provision, better domiciliary care and extended screening programmes seemed minor in comparison with the more wide-reaching proposals. These were contained in a broader antipoverty strategy, involving more progressive taxation and specified minimum and maximum earnings, a comprehensive package of child and family benefits and entitlements, substantial increases in the house building and improvement programme, statutory provision of free school milk and meals, and minimum conditions of work and employment security. As a health policy statement, the report was moving far beyond anything which had gone before, and it was marking out more territory for reform than the whole set of welfare and social policy reforms which accompanied the legislation to establish the national health service.

It was nonetheless the view of the working group that in making these recommendations: "[we have] tried to confine ourselves to matters which are immediately practicable, in political, economic and administrative terms' [DHSS 1980:348]. The (Conservative) government of the day did not agree; the print run of the report was severely restricted, and it was eventually made accessible to a wide audience only by means of independent publication [Townsend and Davidson 1982]. It would be wrong, however, to assume that criticism of the findings was confined to a Conservative government which predictably perceived

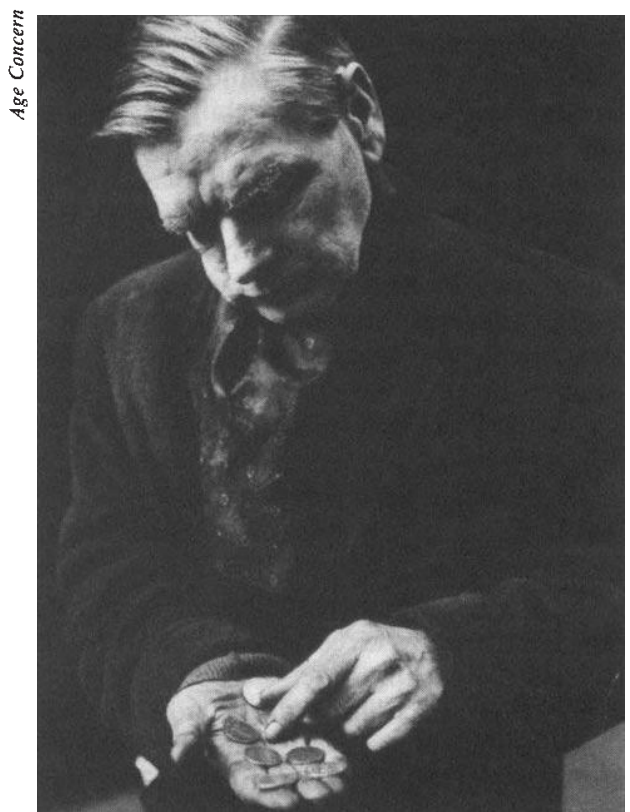

Poverty: still a cause of ill health in Britain.

the report's findings and proposals to be out of step with the general thrust of its own policies. The report was also criticised from the other end of the political spectrum [see, for example, Davis 1982, Greaves 1982]. Deep-rooted ambiguities can be traced in its methods and analysis. It draws a clear distinction between the existence of material inequalities and the processes which give rise to them, processes which are deeply embedded in the pattern of social and economic organisation, in the distribution of power, influence and ownership. As it clearly states, to address the facts of unequal material circumstance without acknowledging the underlying structure which may promote, and even depend upon, the continuing existence of such inequalities is simply to adopt the ameliorative approach which has become a characteristic of much of social medicine and social policy, and which has coexisted with the observed continuation and possible widening of health inequalities. As Bertolt Brecht writes in 'A worker's speech to a doctor':

The pain in our shoulder comes

You say, from the damp; and this is also the reason

For the stain on the wall of our flat.

So tell us:

Where does the damp come from?

Bertolt Brecht [1976] 


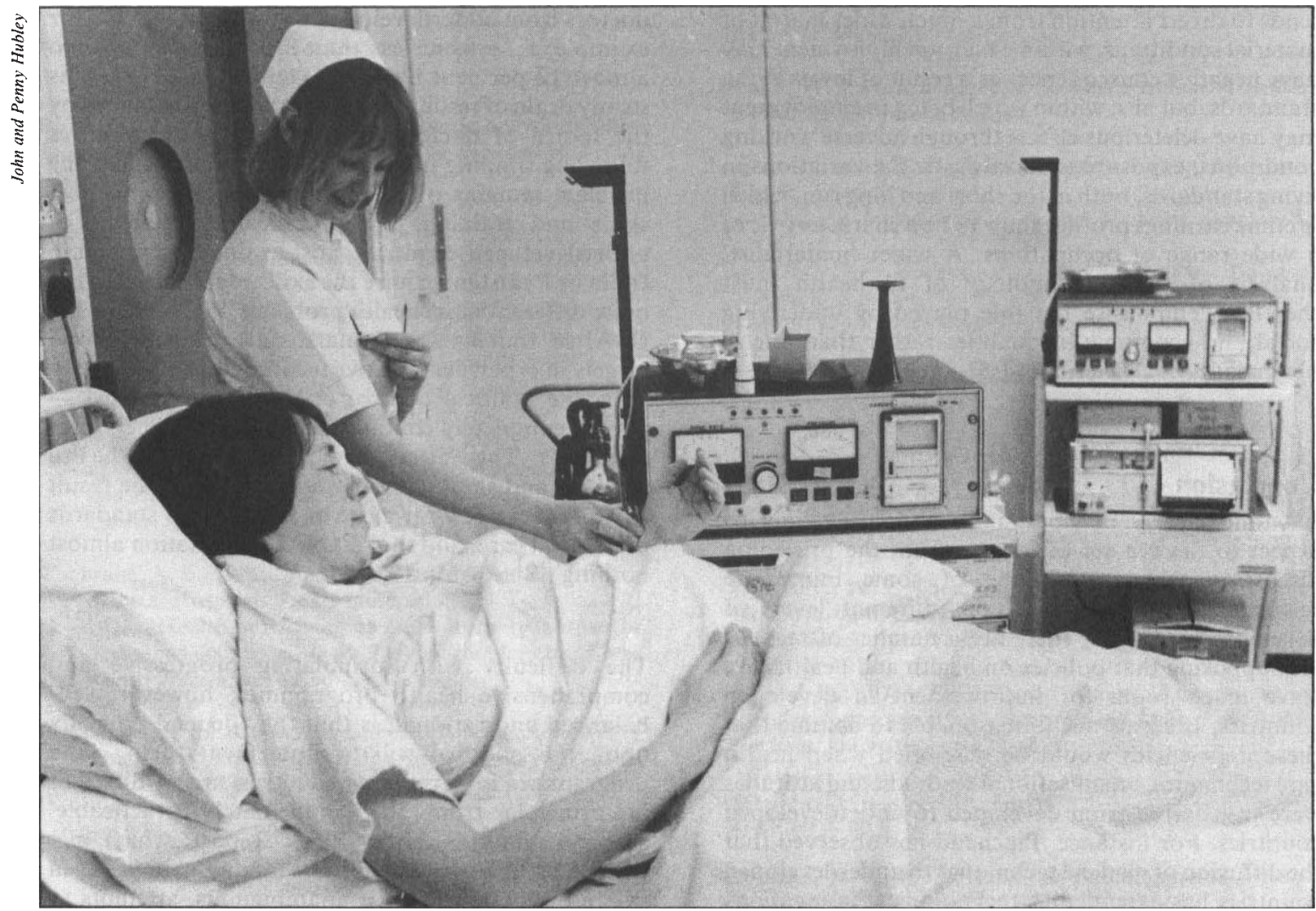

The British national health service: a comprehensive service worthy to be maintained and improved.

The Black Report identifies the ineluctable effects of material circumstances on the observed patterns and trends in health inequalities, and notes the extent to which the generation and maintenance of such material differences are important, perhaps dependent, characteristics of social and economic structure.

On the one hand, the Black Report clearly identifies the theoretical problems associated with the ameliorative approach, and concedes by implication that a genuine attempt to tackle the root causes of health inequalities would lead inevitably to a head-on collision with the interests vested in the present social and economic structure. Yet, on the other hand, the report then formulates a set of policy recommendations whose method of implementation (incremental legislative change) is completely with in the ameliorative tradition, but whose contents essentially state the need to dismantle much of this social and economic structure. To paraphrase Tudor Hart, it seems to have redefined the legitimate territory of health policy, but offered no convincing way of occupying or indeed reaching this territory.
Despite these apparent contradictions between analysis and recommendation, it would be foolish to deny that the broad scope of the Black Report greatly facilitates efforts to place in perspective a number of other contributions to the debate on the effects of the social and economic structure on health. Perhaps the most highly charged area in this respect has concerned the effects of unemployment on health, a debate largely initiated and sustained by the work of Brenner [1973, 1977, 1979]. At the risk of distorting by oversimplification, the central tenet of Brenner's work has been that fluctuations in the level of unemployment are associated with corresponding fluctuations in mortality rates, the casual connection being a form of 'stress' which exerts its influence not simply on the unemployed themselves but on the population as a whole. Discussion of this work has tended to focus on the statistical methods used and the interpretation of the findings. There are also, however, profound conceptual difficulties related to the wider causes of ill health as outlined above. Unemployment may have a negative impact on health through psychological stress induced by the threat of it. Yet a focus on 'stress' 
tends to divert attention from a much wider matrix of material conditions, within which unemployment may have negative consequences as a result of lower living standards, but also within which being in employ ment may have deleterious effects through adverse working conditions, exposure to hazards, or the variations in living standards, both in the short and long run, which lifetime earnings profiles show to be a characteristic of a wide range of occupations. A wider 'materialist' analysis of the epidemiology of ill health must therefore 'emphasise the role played by underlying social and economic inequalities rather than unemployment per se' [Stern 1981:57-8].

\section{Conclusion}

It would clearly be both naive and misleading to expect to draw a set of lessons from the preceding discussion which might be of some immediate relevance to societies at quite different levels of development. Clearly there are a number of reasons for supposing that policies on health and health care leave much room for improvement in developed countries. It seems not unreasonable to assume that these deficiencies would be magnified when health care techniques, organisational methods, and attitudes were transferred from developed to underdeveloped countries. For instance, Piachaud has observed that the diffusion of medical techniques to underdeveloped countries has extended to technological innovations which "impose a severe strain on the health service resources of even the most prosperous nation' [Piachaud 1979:629], and which in some instances have never been properly evaluated for their clinical effectiveness or economic efficiency. Of 40 countries included in Piachaud's study of the diffusion of eight modern medical techniques - including for example computerised body scanners and open-heart surgery - all $\mathbf{4 0}$ had acquired at least one of the techniques, and three had acquired all of them. This rate of diffusion seemed to be more rapid than that of many non-medical developments, such as television or computers. Apart from the direct financial consequences, it is an intrinsic characteristic of the use of such expensive techniques that any benefits from them must be extremely unequally distributed: most were located in a teaching hospital or government institution in a major city, accessible only to a geographically and socially small segment of the population.

A key element in the transference of medical techniques, attitudes, training and organisation is the international movement of medical labour. One side of this is the loss of trained medical staff from underdeveloped to developed countries, a trend which does not seem to be diminishing: the proportion of doctors from underdeveloped countries in the UK, for example, rose from less than 8 per cent in 1967 to almost 12 per cent by 1979 [Mejia et al 1979]. This steady drain of resources is partly counter-balanced by the return of doctors to underdeveloped countries following training in industrialised countries, but the problem remains of the mismatch between medical skills and training, and the health problems of underdeveloped countries. Just as doctors trained in India or Pakistan acquire the skills more suited to the quite different mass health problems of the UK or the USA, so Indians or Ghanaians are trained abroad largely in expensive curative techniques, and return to 'effective political control of the health systems almost completely conditioned by developed country standards. They attach low status to public health work - and shun administration ... with the result that the lucky few get more or less western standards of medical care, and the rest of the population almost nothing' [Sharpston 1973:456-7].

The difficulty with formulating progressive and comprehensive health programmes, however wellbalanced and rational, is that they depend crucially upon the political will to implement them. Such programmes in developing countries are no different in principle from the 'immediately practicable' recommendations of the Black Report, which met with such official indifference and hostility. Even where the political will is unambiguous, attempts to promote health reform can encounter serious obstacles. Bossert's account of health policy in postrevolutionary Nicaragua notes that 'the new team of policy makers was made up almost entirely of physicians whose training was primarily curativeoriented', who had little knowledge of preventive and public health, and who therefore were 'especially likely to respond to a demand for curative care', while those "who previously had benefited from these privileged services found it difficult to accept less adequate services in the unified system, and they made public their complaints' [Bossert 1981:230]. How much more difficult, then, when the will to attempt such changes does not exist. 'Few things could be further from the truth' observed England, than that 'governments are universally committed to improving the health of their populations and that the health planner operates simply as a technical expert within such a context of commitment' [England 1978:158]. Medicine continues not to occupy the territory which is clearly of fundamental importance in combatting disease, and has too often not yet even staked its claims. In these circumstances, 'our' past holds an irresistible lesson. To state this is not to lay oneself open to accusations of being patronising, for it is a lesson which both 'we' and 'they' seem reluctant to learn. 


\section{References}

Abel-Smith, B., 1981, 'Health and economy', Health and Economy, no 2, Antwerp

Bossert, T. J., 1981, 'Health policy making in a revolutionary context: Nicaragua, 1979-81', Social Science and Medicine, vol 15c, pp 225-31

Brecht, Bertolt, 1976, Poems 1913-1956, edited by John Willett and Ralph Manheim, Eyre Methuen, London

Brenner, M. H., 1973, 'Fetal, infant, and maternal mortality during periods of economic instability', International Journal of Health Services, vol 3 no 2, pp 145-159

-1977, 'Health costs and benefits of economic policy', International Journal of Health Services, vol 7 no 4, pp 581-623

-1979, 'Mortality and the national economy: a review, and the experience of England and Wales, 1936-76', Lancet, ii, pp 568-73

Cochrane, A. L., 1971, Effectiveness and Efficiency, Nuffield Provincial Hospitals Trust, London

-1978, 'Health service input and mortality output in developed countries', Journal of Epidemiology and Community Health, vol 32 no 3, pp 200-205

Cooper, M. H. and Culyer, A. J., 1971, 'An economic survey of the nature and intent of the British national health service', Social Science and Medicine, vol 5, pp 1-13

Davis, C., 1982, 'Criticising epidemiology: some notes on inequality', Radical Community Medicine, no $11 / 12$

DHSS, 1980, Inequalities in Health: Report of a Research Working Group, Department of Health and Social Security, London

Eckstein, H., 1958, The English Health Service, Harvard University Press, Boston

England, R., 1978, 'More myths in international health planning', American Journal of Public Health, vol 68 no 2 , pp 153-9

Gray, A. M. and Hunter, D. J., 1983, 'Priorities and resource allocation in the Scottish health service: some problems in planning and implementation', Policy and Politics, forthcoming
Greaves, D., 1982, 'The Black Report and materialism', Radical Community Medicine, no $11 / 12$

Illich, I., 1975, Medical Nemesis: the Expropriation of Health, Calder and Boyars, London

McKeown, T., 1965, Medicine in Modern Society, Allen and Unwin, London

-1974, An Introduction to Social Medicine, Blackwell, Oxford

-1976, The Modern Rise of Population, Edward Arnold, London

-1979, The Role of Medicine, Blackwell, Oxford

Mejia, A., et al, 1979, Physician and Nurse Migration, WHO, Geneva

Morris, J. N., 1959, 'Health and social class', Lancet, i, pp $87-90$

-1979, 'Social inequalities undiminished', Lancet, 13 January

Navarro, V., 1975, 'The industrialisation of fetishism or the fetishism of industrialisation: a critique of Ivan Illich', Social Science and Medicine, vol 9 pp 351-63

Piachaud, D., 1979, 'The diffusion of medical techniques to less developed countries', International Journal of Health Services, vol 9 no 4, pp 629-43

Seers, D., 1977, 'Back to the ivory tower?', IDS Bulletin, vol 9 no 2 , pp 6-11

Sharpston, M. J., 1973, 'Health and development', Journal of Development Studies, vol 9 no 3, pp 455-60

Stern, J., 1981, 'Unemployment and its impact on morbidity and mortality', Discussion Paper 93, Centre for Labour Economics, London School of Economics

Townsend, P., 1974, 'Inequality and the health service', Lancet, i, pp 1179-90

-and Davidson, N., 1982, Inequalities in Health, Penguin, London

Tudor Hart, J., 1981, 'A new kind of doctor', Journal of the Royal Society of Medicine, vol 74, pp 871-83

Wrigley, E. A. and R. S. Schofield, 1981, The Population History of England, 154l-1871: a Reconstruction, Arnold, London 